\title{
The Training Skills of Military Officers in Treating Al-Istiqlal University Students from the Viewpoint of the Students Themselves
}

\author{
Dr. Amer Saber Shehadeh \\ Assistant Professor, Al-Istiqlal University, Palestine \\ Email: amershehadeh2008@yahoo.com \\ Dr. Mohammad Taleb Dabous \\ Associate Professor, Al-Istiqlal University, Palestine \\ Email: mddabous@hotmail.com \\ Dr. Nader Taleb Shwamreh \\ Assistant Professor, Al-Istiqlal University, Palestine \\ Email: nshwamreh@yahoo.com
}

\begin{abstract}
:
The study aimed to know the skills of military training officers in dealing with the students of Al-Istiqlal University from the viewpoint of the students themselves. In order to achieve the aim of the study, a tool was developed to measure the extent of the availability of human and selfskills by the training officers. The tool is a questionnaire which included (33) items distributed on two axes and six domains.

The study was conducted on a random sample consisting of (225) male and female students from Al-Istiqlal University students. After collecting the data of the study, they were statistically treated by using the Statistical Packages for Social Sciences program (SPSS). The study reached a number of results the most important of which was that the degree of the availability of human and self-skills by the training officers from the viewpoint of the students themselves was medium.
\end{abstract}


The results also showed that there are no statistically significant differences at the significance level of $(\alpha \leq 0.05)$ in the degree of the availability of the self and human skills by the training officers in the security apparatuses in dealing with the students of Al-Istiqlal University from the viewpoint of the students themselves which are due to the variable of gender, whereas there were statistically significant differences in the variable of the faculty in the axis of the self-skills in favour of the medium community college as compared with the faculty of human sciences and the faculty of administrative sciences. Also there were statistically significant differences in the variable of the study year level in all the axes of the study and the total degree in favour of the first year as compared with the students of the third and fourth years, and in favour of the second year over the third year.

Keywords: Skill, Military Training Officers, Al-Istiqlal University

هدفت الدراسة إلى التعرف على مهار ات ضباط التدريب العسكري في التعامل مع طلبة جامعة الاستقلال من وجهة نظر الطلبة أنفسهم، ولتحقيق هدف الدراسة تم تطوير أداة لقياس مدى نوفر المهار ات الإنسانية والذاتية لدى ضباط التدريب و هي عبارة عن استبانة، اشتملت على (33) فقرة، موز عة على محورين وستة مجالات. أجريت الدر اسة على عينة عشو ائية مكونة من (225) طالبا وطالبة من طلاب جامعة الاستقلال. وبعد جمع بيانات الدر اسة، عولجت إحصائياً باستخدام برنامج الرزم الإحصائية للعلوم الاجنماعية (SPSS). وقد توصلت الدر اسة إلى مجمو عة من النتائج كان من أهمها أن درجة توفر المهارات الإنسانية والذاتية عند ضباط التدريب من وجهة نظر الطلبة أنفسه كانت

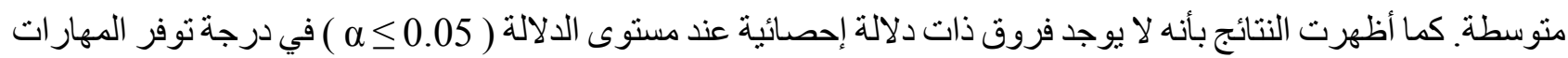
الذاتية والإنسانية لاىى ضباط التدريب في الاجهزة الامنية في التعامل مع طلبة جامعة الاستقلال من وجهة نظر الطلبة أنفسهم تعزى لمتغير الجنس، في حين كان هنالك فروق ذات دلالة إحصائية في متغير الكلية في محور المهار ات الذاتية لصالح كلية المجتمع المتوسطة مقارنة بكليتي العلوم الإنسانية والإدارية. كذلك وُجدت فروق ذات دلالة إحصائية في متغير مستوى السنة الدر اسية في جميع محاور الدر اسة والدرجة الكلية ولصالح سنة أولى مقارنة بطلاب سنة ثالثة ور ابعة، ولصالح سنة ثانية على 


\section{Theoretical background}

The training and rehabilitation of human cadres in all domains of life is considered the basis for any successful work. It is the thing which achieves development and advancement in all the sectors of the state, whether this is in the training or teaching or the defence affairs or the production or service affairs or others of the remaining sectors.

Training is defined as a process which is built on a precise organizing through which the experiences and knowledge are transferred to increase the skills and information of those who are targeted by training or to change their behaviours and convictions to achieve the main aims of the training the realization of which depends on the degree of efficiency of the trainers and leaders and their exerted efforts.

Because the level of training and its attaining its purpose cannot be advanced in the absence of a strategy which sets before its eyes the building of the officer, the non-commissioned officer and the soldier on a sound and developed basis which implants sacrifice and redemption in their spirits. Training in the military and the security sides has been considered one of the basic props on which the security forces, and the administrative technical units which aid them are built, and which aims to develop all the planning abilities and develop the skills and knowledge of the officers, non-commissioned officers and soldiers in all their specializations. It is also interested in rectifying and changing the behaviours of security personnel and to make the training programs which are generally adopted succeed. This depends on rehabilitating, empowering and making the trainers and leaders acquire skills, knowledge and abilities which are emulated by the trainee students (Kurdieh, 2011; Al-Tanani, 2010).

There are many theories which include the properties which must be available in the leader or the official or the trainer. Amon these theories is the theory of traits which is based on that there is a number of traits and properties which, if they are available in the person, then he is qualified to become a leader (Sheeha, 1983 \& Darweesh, 1988). Some are bodily such as: height, age, and weight. Some are mental such as: intelligence, memory power and thinking. Some are affective such as: emotional maturity, and some are social such as: establishing good contacts with the group (Othman, 1997). This is what Kan'aan, 1985\& Shareef, 1987) and many other have indicated. 
Situation theory which indicates that the effect of the leader on the individuals of the group is connected to a certain situation in a certain circumstance (Humaid \& Al-Ma'aaz, 1986 \& AlWaheebi, 2005). In this connection, Al-Tajm \& Al-Sewat, 1995) added that the situations are the ones which make leaders. As for the interactive theory, it combines between the two previous theories whereby it indicates the interaction of with personality traits with the elements of the situation and the properties of the group. (Al-Jayyousi \& Jad-Allah, 2000).

It is worth mentioning that the successful officer who enjoys human and self-skills in addition to commitment to the good rules of military control and connection has a basic and active role in raising the morale of the elements of the fighting units and formations, in addition to increasing the confidence of the individuals in themselves and in their leadership. Therefore, complete precision should be intended when choosing the proficient trainers who are professionals for the training task whether they are from the same teaching institution or by seeking the help of trainers from other institutions or other units (Matin and others, 2010; Dosh, 2006; Al-Thuwaiby, 2005).

Also the success of the training process does not depend only on the teaching material or the furnishings and the facilities only, rather it is concentrated in a bigger form in the proficiency of the trainer, his intelligence and his good conduct. (Military Training Commission-Palestine 14/3/2020). http://www.gmtc.sec.ps/

Also military training makes the person accustomed to patience and bearing and it develops quick intuition. It works on implanting the values of discipline, loyalty, intrepidity and group work, as well as reinforcing self-confidence, and subsequently, it contributes in building the active military personality. (Sultan Qaboos Academy for Police Sciences 14/3/2020) http://sqaps.edu.com/?p=3442

There is no agreement on what the military and security training means to the persons and trainees. The points of view differed and they were distributed on the following qualities: discipline, prior preparation, group performance and effectiveness. (Flethcher \& Chatelier, 2000). What follows are some traits and skills which the leaders and the trainees should have and acquire:

1. Loyalty, faithfulness and sincerity: Loyalty to God, the homeland and the people and no others. As a leader he should reflect in all his conduct sincerity and loyalty to his 
subordinates and to his military institution in which he works. So the faith of the leader in his God, his homeland, his nation and his question which he defends should be deep.

2. Tactfulness and good treatment of the subordinates: The leader should enjoy the ability to talk actively and to arrange his ideas and to present them in a distinguished way, and treating the others with respect, politeness and courtesy, and the ability to comprehend the others.

3. Calmness and self-control: The leader has to control his nerves and to conduct in an unruffled way specially at the moment of making decisions and in front of the subordinates. He should be firm in implementing his decisions. Fahmi added as was mentioned in AbuHashem (2007) the ability of self-control is one of the conditions of mental health. The normal individual is the one who can control his desires and he should be able to satisfy and postpone fulfilling his needs, while (Gililand, 1989) considered these qualities as selfpower which is added to the person.

4. Faith in the goals and purposes: The leader who does not believe in the goal and in what he wishes to achieve does not only frustrate himself, but rather he frustrates the resolution of his subordinates. For the leadership is not a rush or fluent speech or bravery or a skill, rather it is knowing the possibilities and exploiting them and putting every one of them in the place that suits him, and disseminating the idea of power and equality among them, distributing responsibilities among them and let them all participate in serving the public interest provided that every individual of them remains within his specialization.

5. Modesty: Much talking about the (I) is killing for the leader and it is a word which is not liked by the subordinates, because in it there is the feeling of haughtiness and superiority and it ascribes successes to the self only without respecting the feelings of others and magnifying the achievements. It suffices to know that one person cannot achieve and cannot realize all the successes.

6. Effectiveness: Implementing the decisions, following them up and removing the difficulties before them by the leader are indicators of his effectiveness and his interaction with the task. Also effectiveness in implementing difficult tasks is one of the biggest motives for the subordinates to work specially when the leader implants in them that there is no impossible thing in front of the powerful determination.

7. The good example: Without it the leader cannot enjoy the trust and respect of his followers, aides and subordinates. The noble goals cannot be achieved if the leader is not an example for his subordinates in the sublime and good actions. 
Among the qualities is the good example. (Al-Musallah (the armed Magazine 14/3/2020) http://www.almusallh.ly/ar/thought/40, and it is represented in the ability to hear and listen very well and oral persuasion (Al-Qurni, 1426, Hijra).

Darweesh and Takla (1995) added other traits the most important of which are: fluency of speech and eloquence, power of affecting, strength of personality, zeal, dedication, calmness, not being emotional, military control and connecting, besides truth, honesty and justice.

\subsection{Problem of the Study and Its Questions:}

The skills of the training officers at Al-Istiqlal University in dealing with the students are considered among the topics which are worthy of interest and study. The researchers who work at Al-Istiqlal University in the academic domain and through their observation of the military training officers in how they deal with the University students,

it became prominent to them the importance of knowing to what degree the human and the self-skills are available in dealing with the University students. According to that, the questions of the study can be specified as follows:

1. To what extent are the human skills available among the officers of military and security training in dealing with students of Al-Istiqlal University from the viewpoint of the students themselves?

2. To what extent are the self-skills available among the officers of military and security training in dealing with the students of Al-Istiqlal University from the viewpoint of the students themselves?

3. Are there statistically significant differences at the significance level of $(\alpha \leq 0.05)$ in the degree of the availability of the self and human skills among the training officers in dealing with the students of Al-Istiqlal University from the viewpoint of the students themselves which are due to the variables of (gender, faculty, and level of the study year)?

\subsection{Hypotheses of the Study:}

1. There are no statistically significant differences at the significance level of $(\alpha \leq 0.05)$ in the degree of the availability of the self and human skills among the training officers in dealing with the students of Al-Istiqlal University from the viewpoint of the students themselves which are due to the variable of gender (male, female). 
2. There are no statistically significant differences at the significance level of $(\alpha \leq 0.05)$ in the degree of the availability of the self and human skills among the training officers in dealing with the students of Al-Istiqlal University from the viewpoint of the students themselves which are due to the variable of faculty (humanities, law and police sciences, administrative sciences, medium community college).

3. There are no statistically significant differences at the significance level of $(\alpha \leq 0.05)$ in the degree of the availability of the self and human skills among the training officers in dealing with the students of Al-Istiqlal

a. University from the viewpoint of the students themselves which are due to the variable of the study year level (first, second, third, fourth).

b.

\subsection{Aims of the Study:}

The study aimed to know the following:

1. Shedding the light on the extent of the availability of the human and self-skills which the training officers at Al-Istiqlal University for the security sciences have in dealing with the students.

2. Reinforcing the effect of each of the variables of gender, faculty and level of the study year on the extent of the availability of the human and self-skills which the training officers at Al-Istiqlal University for the security sciences have.

3. Providing the officials at Al-Istiqlal University with studied scientific results about the treatment of the training officers with the University students for the sake of improving the human and self-skills of the military training officers at Al-Istiqlal University.

\subsection{Importance of the Study:}

The importance of the present study is prominent from the responsibility which is entrusted to the military training officers and the nature of their work which depends on direct dealing with the University students every day. The importance of the study is represented in the following: 
1. The Theoretical Importance: It is represented in enriching the scientific knowledge and providing the Arab library with what is useful in the domain of developing the skills of the treatment by the military training officers of the University students.

2. The Practical Importance: It is represented in that the study will contribute in making the military training officers and the officials at the University know how the military training officers deal with the University students and for the sake of planning practical programs for advancing the level of the skills which the officers should have in how to deal with the University students.

\subsection{Limitations of the Study:}

Place Limitation: This study was conducted at Al-Istiqlal University-Jericho, Palestine.

Time Limitation: This study was applied in the second study semester of the year 2019/2020.

Human Limitation: The students of Al-Istiqlal University for security sciences.

\subsection{Procedural Definitions:}

Skill: The ability to undertake a certain work in a way which is characterized by precision, ease and control in the effort and time which are exerted (Kan'aan, 2002).

\section{Human Skills:}

This means the ability of the leader to interact with his subordinates, coordinating their efforts and creating the spirit of group work among them.

Researchers procedurally define them as being the art of the military training officers' dealing with the students of Al-Istiqlal University concerning building good relations with them through taking interest in their inclinations, their feelings and accepting their suggestions and constructive criticisms. They are measured through the questionnaire which is prepared for measuring the availability of the skills (listening, talking and solving the problems).

\section{Self-Skills:}

They indicate to the group of the skills which are represented in performing the required tasks and works with ease and facility through training in practising the skill until it reaches the required mastery which in turn leads to personal and social congruence. 
Researchers procedurally define it as being a group of personal traits, mental abilities and self-control which the military training officer should have in order to deal effectively with the others in specific situations in a way which achieves certain goals whether pertaining the person or the other persons.

Al-Istiqlal University: It is the Palestinian Academy for Security Sciences. It was established in (1998) as an institution which is specialized in rehabilitating and graduating scientific cadres have a high efficiency to supply the Palestinian security apparatuses with their needs for security, police and military specializations until it was accredited by the Palestinian Ministry of Higher Education.

\section{Methods and Procedures:}

\subsection{Methodology of the Study:}

The researchers in this study used the descriptive analytical methodology which depends on studying the phenomenon in the present time as it actually is. This is the suitable and best methodology for such studies.

\subsection{Population of the Study:}

The population of the study consisted of all the students of Al-Istiqlal University in the second study semester of the study year 2019/2020 A.D. whose number was (1459) male and female students. This is according to the statistical records of the Deanship of Admission and Registration at Al-Istiqlal University.

\subsection{Sample of the Study:}

The sample of the study consisted of (225) male and female students at Al-Istiqlal University from the students of the second study semester for the study year 2019/2020. Table (1) indicates the distribution of the study sample according to its variables. 
Table (1) Distribution of the Study Sample According to Its Variables

\begin{tabular}{lcc} 
Variable & $\begin{array}{c}\text { Frequency } \\
\text { Gender }\end{array}$ & Percentage \% \\
Male & 150 & $66.7 \%$ \\
Female & 75 & $33.3 \%$ \\
Total & 225 & $100 \%$ \\
\hline Faculty & & \\
Humanities & 134 & $59.6 \%$ \\
Law and Police Sciences & 44 & $19.6 \%$ \\
Administrative Sciences & 36 & $16.0 \%$ \\
Medium Community College & 11 & $4.9 \%$ \\
Total & 225 & $100 \%$ \\
\hline
\end{tabular}

Level of Study Year

\begin{tabular}{lcc} 
First Year & 29 & $12.9 \%$ \\
Second Year & 42 & $18.7 \%$ \\
Third Year & 62 & $27.6 \%$ \\
Fourth Year & 92 & $40.9 \%$ \\
\hline Total & 225 & $100 \%$
\end{tabular}

\subsection{Tool of the Study:}

The two researchers got acquainted with the theoretical literature and the previous studies which are related to the topic of the study. The researchers benefited from Al-Tanani (2010) study and Kurdieh (2011) study in building the items which are related to the skills of the military training officers in how to deal with the University students. The questionnaire of the study consisted of three sections which are:

The First Section: Personal data of the respondent (gender, faculty, level of the study year). The Second Section: The axis of human skills and it consists of three domains which are: (listening, talking, and solving problems).

The Third Section: It concerns the axis of the self-skills which consists of three domains which are :(personal traits, mental abilities, self-control). 
Table number (2) indicates the domains and axes of the questionnaire and the number of the items of every domain:

Table (2): Axes, Domains, and Number of the Questionnaire Items

Number of Axis Domain Number of Items

First Axis: Human Skills

$\begin{array}{lll}\text { First Domain } & \text { Listening Skill } & 6 \\ \text { Second Domain } & \text { Communication Skill } & 6 \\ \text { Third Domain } & \text { Skill of Solving Problems } & 6\end{array}$

Sum of the items of the first axis 18

Second Axis: Self Skills

First Domain The domain of personal traits 5

Second Domain The domain of mental abilities 5

Third Domain The domain of self-control 5

Sum of the number of items of the second axis $\quad 15$

Total sum of the questionnaire items

33

The researchers adopted the five-scale Lickert Measure to specify the extent of the availability of human skills among the military training officers in dealing with the students of Al-Istiqlal University from the viewpoint of the students themselves through responding to the measure. The following weights were adopted (very high degree $=5$, high degree $=4$, medium degree $=3$, low degree $=2$, very low degree $=1$ ).

Also the value of the categories of the graduated five-scale measure as follows:

1 - 1.8 very low degree

$1.81-2.6$ low degree

$2.61-3.4$ medium degree

3.41 -4.2 high degree

4.21 -5 very high degree 


\subsection{Validity of the Instrument:}

The questionnaire was presented to a group of specialized referees. They were asked to give their opinion concerning the items of the questionnaire in terms of their formulation, their linguistic preciseness and the extent of their suitability and belonging to the domain. This was either by agreement or modifying their formulation or omitting them because they are not important. The opinion of the majority was taken into account in the process of refereeing the items of the instrument, whereby the questionnaire in its final form became consisting of (33) items and four each items there are five alternatives.

\subsection{Reliability of the Instrument:}

The reliability coefficient was made for the items of the questionnaire by using the Cronbach Alpha Coefficient. Table (3) indicates the reliability coefficients for each domain and the total reliability coefficient:

Table (3): Reliability Coefficients

Number of Axis

the Domain

Reliability Coefficient

The First Ais: Human Skills

The First Domain

Hearing Skill

0.895

The Second Domain

Listening Skill

0.789

The Third Domain

Skill of Solving Problems

0.859

\section{Total Reliability Coefficient for the First Axis 0.934}

The Second Axis: Self-Skills

$\begin{array}{llc}\text { The First Domain } & \text { Domain of Personal Traits } & 0.814 \\ \text { The Second Domain } & \text { Domain of Mental Abilities } & 0.878 \\ \text { The Third Domain } & \text { Domain of Self Control } & 0.856\end{array}$

Total Reliability Coefficient for the Second Axis $\quad 0.935$

Total Reliability Coefficient for All of the Items of the Questionnaire 0.962 
It is noticed from Table (3) that the reliability coefficient for each of the domains was suitable, and that the total reliability coefficient came with a high degree (0.96). These values of the reliability coefficient are considered high values which allow the application of the instrument.

\subsection{Variables of the Study:}

The study included the following variables:

A- The Independent Variables:

Gender: It has two levels (male, female)

Faculty: It has four levels (humanities, law and police sciences, administrative sciences, medium community college)

Level of study year: It has four levels (first year, second year, third year, fourth year)

B- The Dependent Variable:

The degree of the responses of the individuals of the sample on the instrument of the study related to the extent of the availability of human skills among the military training officers in dealing with the students of Al-Istiqlal University from the viewpoint of the students themselves.

\subsection{Statistical Treatments:}

In order to statistically treat the data, the Statistical Packages for the Social Sciences (SPSS) computerized program was used. This was by using the following descriptive and analytical statistical treatments:

-Arithmetic means and standard deviations.

-The T-test for the independent operations.

-One Way ANOVA.

-The Less Statistical Significant (LSD) test for the dimensional comparisons.

\section{Presenting Results}

Results related to the first question of the study the text of which is: What is the extent of the availability of human skills among the military training officers in dealing with the students of Al-Istiqlal University from the viewpoint of the students themselves? 
To answer the question, the arithmetic means and the standard deviations were calculated for the extent of the availability of human skills among the military training officers in dealing with the students of Al-Istiqlal University from the viewpoint of the students themselves for all of the domains of the human skills axis.

Tables from (4) - (7) indicate these results.

First: The Domain of the Hearing Skill

Table (4): Arithmetic Means and Standard Deviations of the items of the first domain related to the hearing skill among the military training officers

Item Number Item Arithmetic Standard Estimation
Mean
Deviation
Degree

1. Military training officers listen

To the students without interruption

$2.83 \quad 1.18 \quad$ Medium

2. Military training officers concentrate

Their interest on what the student says

$2.67 \quad 1.11 \quad$ Medium

3. Military training officers are interested

In the student's feelings and conversations

$2.51 \quad 1.13 \quad$ Low

4. Military training officers encourage students

To express their ideas

1.20 Medium

5. Military training officers have the ability to

Comprehend and understand what is said

$3.24 \quad 1.12 \quad$ Medium

6. Military training officers make the students

Feel that they recognize what the student says

$3.101 .15 \quad$ Medium

Total Degree $\quad 2.89 \quad 0.93 \quad$ Medium

The results mentioned in Table (4) indicate that the total degree of the extent of the availability of human skills among military training officers in dealing with the students of Al-Istiqlal University from the viewpoint of the students themselves for the domain of listening has achieved a medium level with an arithmetic mean of (2.89). 
Item (5) the text of which is (military training officers have the ability to comprehend and understand what is said) has got the highest arithmetic mean which is (3.24) which is a medium degree, whereas item number (3) the text of which is (military training officers are interested in the student's feelings and conversations) attained less than a medium which is (2.51) which is a medium degree.

The researchers interpret this result in that military officers due to their varying experiences in the field have a big ability to listen to others, to understand the details of their suffering or their complaint or their daily demands, or for the sake of gathering information related to the nature of work from the students. This one of the alphabets of military work which imposes upon them continuous communication with the different military regiments to deal with what is new in successive issues based on a strict military ranking system which graduates from the base of the pyramid to its summit. This is what was reflected by the responses of the individuals of the sample in a medium degree. This result agrees with the study of (Martin \& Others, 2010) while it differed from Al-Tanani (2010) study and Al-Thuwaiby (2005) study whereby the listening skill in the two studies was big.

\section{Second: The Domain of the Speaking Skill}

Table (5): The Arithmetic Means and the Standard Deviations of the Items of the Second Domain Which is Related to the Speaking Skill among Military Training Officers Item number

Item Arithmetic Standard Estimation

$$
\text { Mean Deviation Degree }
$$

7. Military

training officers do not

3.40

$1.10 \quad$ Medium

Find difficulty in talking to the students
8. Military training officers do not find
Medium

Difficulty in praising and being courteous to others

9. Military training officers select clear words

$3.16 \quad 1.22$

Medium

To express their thoughts

10. The students listen to military training 
Officers when they talk
11. Military training officers enjoy self-confidence
3.71
1.09
High

When they talk to the students
12. Military training officers talk to the students
3.42
1.13 High

In a style which enables them to comprehend what they say

$\begin{array}{llll}\text { Total Degree } & 3.41 \quad 0.81 \quad \text { High }\end{array}$

The results mentioned in Table (5) indicate that the total degree of the extent of the availability of human skills among military training officers in dealing with the students of AlIstiqlal University from the viewpoint of the students themselves for the domain of the speaking skill has achieved a high level and with an arithmetic mean of (3.41). Item (10) the text of which is (the students listen to the military training officers when they talk) got the highest arithmetic mean which is (3.84) and it is a high degree, whereas item number (8) the text of which is (military training officers do not find difficulty in praising and being courteous to others) obtained the least medium which is (2.87) and this is a medium degree.

The researchers interpret this result in that the students of Al-Istiqlal University recognize the extent of the importance of talking and daily communication with their leaders and their trainers, through official channels which are agreed upon in the international military formations and academies, in several methods including: oral and written communiques and the orders.... etc. This is what their responses to the instrument of the study reflected with a high degree.

The researchers also ascribe the result to the fact that the nature of the job of the military officers is characterized by giving military instructions and orders to the students whereby there is a sort of severity in these orders when talking. Thus the students of the University view that military training officers have high confidence in themselves when they talk to the students and they do not find difficulty in talking to the students.

This result differs from Al-Tanani (2010) study whereby it showed that the degree of the talking skill among police officers for dealing with the public was medium. 
Third: The Domain of Problem Solving Skill

Table (6): Arithmetic Means and Standard Deviations for the Items of the Third Domain Which Is Related to the Problem Solving Skill among Military Training Officers

\begin{tabular}{|c|c|c|c|c|}
\hline Item Number & Item & Arithmetic & Standard & Estimation \\
\hline & & Mean & Deviation & Degr \\
\hline
\end{tabular}

$\begin{array}{llll}\text { 13. Military training officers use } & 3.27 & 1.18 & \text { Medium }\end{array}$

The law to solve problems among students
14. Military training officers possess a suitable
$3.59 \quad 1.12$
High

Background about the legal systems and rules related to their work
15. Military training officers combine between
3.29
1.19 Medium

Firmness and leniency in solving the problems of the students
16. Military training officers have the ability
1.10
High

To lessen the causes of the occurrence of problems

Among the students

17. Military training officers seek the help of those $\quad \begin{array}{lll}3.34 & 1.17 & \text { Medium }\end{array}$

Who are higher in rank than them in solving the problems?

Which face the students
18. Military training officers present evidence
$3.23 \quad 1.13 \quad$ Medium

And proofs when solving the problems of the students

$\begin{array}{llll}\text { Total Degree } & 3.37 \quad 0.88 & \text { Medium }\end{array}$

The results mentioned in Table (6) indicate that the total degree of the extent of the availability of human skills among military training officers in dealing with the students of AlIstiqlal University from the viewpoint of the students themselves has achieved a medium level 
with an arithmetic mean of (3.37). Item (14) the text of which is (military training officers possess a suitable background on the legal systems and rules which are related to their work) obtained the highest arithmetic mean which is (3.59) and it is a high degree. Item number (18) the text of which is (military training officers present evidence and proofs when solving the problems of the students) obtained the least medium which is (3.23) which is a medium degree.

The researchers ascribe this result to the students' recognition of their reality of their daily life which is lived at Al-Istiqlal University, and their direct communication with their trainers to find effective and positive solutions to the different problems and obstacles which face them, and which their military life is not devoid of, and the reality of their daily training, specially that these problems are many and varied, some of them require urgent solutions and others required deferred solutions. This is what their responses to the instrument of the study revealed in a medium total degree. This result agreed with the study of (Matin \& Others, 2010) and the study of (Al-Tanani, 2010).

\section{Fourth: The Total Domain of the Human Skills Axis}

Table (7): The Arithmetic Means and the Standard Deviations for the Items of the First Axis Related to Human Skills among the Military Training Officers

Number

Domain

Arithmetic Standard

Estimation

Mean Deviation Degree

1. Domain of Listening Skill

0.93

Medium

2. Domain of Speaking Skill

3.41

0.81

High

3. Domain of Problem Solving Skill 3.37

0.88

Medium

4. Total Domain for the Axis

Of Human Skills

3.22

0.79

Medium

The results mentioned in Table (7) indicate that the degree of the total domain for the degree of the axis of the availability of human skills among military training officers in dealing with the students of Al-Istiqlal University from the viewpoint of the students themselves has achieved a medium level with an arithmetic mean of (3.22). 
The domain of the availability of the speaking skill came in the first rank with an arithmetic mean of (3.41) and it is high. The domain of the listening skill came in the last rank with an arithmetic mean of (2.89) and it is medium.

The researchers interpret the responses of the students of Al-Istiqlal University on the degree to which the military officers possess the human skills ( listening, speaking, problem solving) in dealing with them in a medium degree, in that they (human skills) are considered among the factors of the success of the University, achieving its vision and its goals by graduating a distinguished officer who is endowed with all the positive human skills which qualify him to deal with the public, to serve his homeland and his country people following the example of and emulating his trainers. These skills are also considered an essential element of the elements of success and distinction in the public life and in the security work in particular.

Results related to the second question of the study, the text of which is: What is the extent of the availability of the self-skills among the military training officers in dealing with the students of Al-Istiqlal University from the viewpoint of the students themselves?

To answer this question, the arithmetic means and standard deviations were calculated for the extent of the availability of the self-skills among the military training officers in dealing with the students of Al-Istiqlal University from the viewpoint of the students themselves for all of the domains of the axis of the human skills.

Tables from (8) - (11) indicate these results.

First: The Domain of the Personal Traits Skill

Table (8): Arithmetic Means and Standard Deviations for the Items of the First Domain Related to the Skill of Personal Traits among Military Training Officers

Item Number Item Arithmetic Standard Estimation

$$
\text { Mean Deviation Degree }
$$

1. Military training officers enjoy

$3.09 \quad 1.28 \quad$ Medium

Fitness and good bodily strength

2. Military training officers are

Characterized by activity and vitality 
3. Military training officers are interested $4.11 \quad 0.93 \quad$ High In the outside appearance

4. Military training officers have the ability $2.98 \quad 1.14 \quad$ Medium To control the use of the nervous energy

5. Military training officers have the ability 3.53 1.04 High To endure arduous effort in completing the work

Total Degree $\quad 3.37 \quad 0.85 \quad$ Medium

The results mentioned in Table (8) indicate that the total degree for the extent of the availability of the self-skills among the military training officers in dealing with the students of Al-Istiqlal University from the viewpoint of the students themselves for the domain of the personal traits skill has achieved a medium level, with an arithmetic mean of (3.37). Item (3) the text of which is (military training officers are interested in the outside appearance) has got the highest arithmetic mean which is (4.11) and it is a high degree. Item number (4) the text of which is (military training officers have the ability to control the nervous energy obtain the least medium which is (2.98) and it is a medium degree.

The researchers ascribe this result to the fact that there is big interest by those who are responsible for military training officers that the military training officer be qualified whereby he is integrated in sessions to build his bodily capacities and maintain them continuously before he is selected for work in the domain of training at Al-Istiqlal University.

The researchers also ascribe this result to the degree of Al-Istiqlal University students' familiarity and knowledge of the personal qualities and traits which the officer should be endowed with so that he becomes a successful and influential officer who performs his role which is entrusted to him in the perfect way. In addition, the scientific qualification of the students the security, military and police domains made them acquire specialized knowledge of on a group of formal (appearance) and essential personal traits which should be found in the officer in addition to developing and reinforcing them periodically by several training and activating methods. 
Third: The Domain of Mental Abilities

Table (9): The Arithmetic Means and the Standard Deviations of the Items of the First Domain Related to the Skills of Mental Abilities by the Military Training Officers

\begin{tabular}{llccc}
\hline Item number & Item & Arithmetic & Standard & Estimation \\
& Mean & Deviation & Degree
\end{tabular}

6. Military training officers enjoy quickness $3.36 \quad 1.15 \quad$ Medium Of intuition in dealing with emergent situations

7. Military training officers have the mental $\quad 3.30 \quad 1.09 \quad$ Medium Flexibility to accept good suggestions

8. Military training officers enjoy a wide $\quad 3.22 \quad 1.05 \quad$ Medium

Imagination which is capable of visioning and imagining for all the probabilities

9. Military training officers have the ability $\quad 3.17 \quad 1.12 \quad$ Medium

To observe the fine details of the problem

10. Military training officers have the mental $\quad 3.33 \quad 1.07 \quad$ Medium

Readiness for analysis and conclusion from the

Available data and information

\section{$\begin{array}{llll}\text { Total Degree } & 3.27 & 0.90 & \text { Medium }\end{array}$}

The results mentioned in table (9) indicate that the total degree for the extent of the availability of the self-skills among the military training officers in dealing with the students of Al-Istiqlal University from the viewpoint of the students themselves has achieved a medium level, with an arithmetic mean of (3.27). Item (6) the text of which is (military training officers enjoy quickness of intuition in dealing with emergent situation) has obtained the highest arithmetic mean which is (3.36) and it is a medium degree, whereas Item number (9) the text of which is (military training officers have the ability to observe the fine details of the problem) has obtained the least medium which is (3.17) which is a medium degree.

Researchers interpret this result by the fact that the students of Al-Istiqlal University recognize that security, military and police work requires distinguished mental abilities for success and distinction, in addition to specialized abilities in different security domains, for example: training, analysis, search, investigating, enlisting, security sense....etc. 
All of which are skills which require special mental and rational abilities, and in them the officers differ in the extent of their success in their work.

Accordingly, the students of Al-Istiqlal University view that these skills are realized in the military officers (the trained ones) with a medium degree. This is what they reflected through their quickness of intuition in dealing with emergent situations, and the ability to analyse and to conclude and many others. This result agrees with Al-Tanani (2010) study whereas it differed from Al-Qurni (2005) study.

\section{Third: The Domain of Self-Control}

Table (10): Arithmetic Means and Standards Deviations for the Items of the First Domain Related to the Mental Abilities of the Military Training Officers Number

\section{Item}

Arithmetic Standard Estimtion

Mean Deviation Degree

11. Military training officers $\quad 3.12 \quad 1.15 \quad$ Medium

Have the ability to keep calm during difficult situations
12. Military training officers
3.13
1.20
Medium

Have the ability to control emotions resulting from personal problems
13. Military training officers
2.69
1.16
Medium

Have the ability to accept others' criticisms without anger

14. Military training officers have $3.28 \quad 1.09 \quad$ Medium

The ability to control their emotions and directing them

Towards accomplishing the work
15. Military training officers have
2.85
1.17 Medium

The ability to avoid making decisions while they are in a bad mood
Total Degree
3.02
0.92
Medium

The results mentioned in Table (10) indicate that the total degree for the extent of the availability of self-skills among the military training officers in dealing with the students of Al- 
Istiqlal University from the viewpoint of the students themselves for the domain of the skill of self-control has achieved a medium level with an arithmetic mean of (3.02). Item (14) the text of which is (military training officers have the ability to control their emotions and direct them towards accomplishing the work) has obtained the highest arithmetic mean which is (3.28) which is a medium degree, whereas item number (13) the text of which is (military training officers have the ability to accept others' criticisms without anger) has obtained the least medium which is (2.69) which is a medium degree.

Researchers interpret this result by the fact that the University students know the importance of all the workers in the military or security or training field being unruffled and selfcontrolled because this has an extreme importance in taking the right decisions and not being rash or drawn to current emotions and reactions specially that the emergencies of this work are many and various. The medium of their responses on the military training officers being endowed with self-control was at a medium degree.

It is mentioned that the officer's possession of the skill of self-control and the ability to govern and control is one of the criteria of success and which defines the way of his interaction with the different situations.

Fourth: The Total Domain of the Self-Skills Axis

Table (11): The Arithmetic Means and Standard Deviations for the Domains of the Second Axis Related to Self-Skills among Military Training Officers

Number

Domain Arithmetic Standard Estimation

Mean Deviation Degree
1. The domain of personal traits
0.85
Medium
2. The domain of mental abilities
3.27
0.90
Medium
3. The domain of self-control
3.02
0.92
Medium
4. The Total Domain of the Self-Skills Axis
3.22
0.81
Medium 
The results mentioned in table (11) indicate that the degree of the total domain for the degree of the self-skills axis among the military training officers in dealing with the students of AlIstiqlal University from the viewpoint of the students themselves has achieved a medium level with an arithmetic mean of (3.22).

The domain of the availability of personal traits came in the first rank with an arithmetic mean of (3.37) which is a medium degree, and it was followed in the second rank by the domain of the mental abilities with a medium of (3.27) which is a medium degree. The domain of the skill of self-control came in the last rank with an arithmetic mean of (3.02) which is a medium degree.

Researchers ascribe this result and its revolving around the medium degree to the fact that the human personality is one unit which is in harmony in itself and its entity. This is manifested in its social, human, self and mental sides. Also that is considered one of the sides of the sound balanced personality in which one side does not dominate another side, but rather it lives in internal peace and self-tranquillity which are positively reflected in the life conduct in general and in the security and training conduct in particular.

It is worth mentioning that positive personal traits, the unique and distinguished mental abilities, the skill of self-control and emotional control are like standard and criteria on which the success of the individual depends in the different security domains specially the training domains.

The results related to the third question of the study the yest of which is: Are there statistically significant differences at the significance level of (a-0.05) in the degree of the availability of human and self-skills among the military training officers in dealing with the students of AlIstiqlal University from the viewpoint of the students themselves which are due to the variables of (gender, faculty, level of the study year)?

To answer this question, the following hypotheses of the study were examined:

The first hypothesis of the study the text of which is: There are no statistically significant differences at the significance level of $(\alpha \leq 0.05)$ in the degree of the availability of the self and human skills among the military training officers in dealing with the students of Al-Istiqlal University from the viewpoint of the students themselves which are due to the variable of gender (male, female). 
To examine the hypothesis, the researcher used the T-test for two independent groups (Independent t-test), and the results of Table (12) indicate this

Table (12): Results of the t-test for two independent groups to test the significance of the differences according to the variable of gender.

\begin{tabular}{lcccc}
\hline Axis & \multicolumn{2}{c}{ Males $(\mathrm{n}=150)$} & \multicolumn{2}{c}{ Females $(\mathrm{n}=75)$} \\
\multicolumn{2}{r}{ Arithmetic Mean } & S D & Arithmetic Mean & SD \\
Human Skills & 3.2744 & 0.74314 & 3.1044 & 0.86501 \\
Self-Skills & 3.2711 & 0.75826 & 3.1173 & 0.91118 \\
Total Degree & 3.2729 & 0.71428 & 3.1103 & 0.84663 \\
a value & & Significance Level* & \\
1.455 & & 0.148 & \\
1.260 & & 0.210 & \\
1.429 & & 0.156 & \\
\end{tabular}

* Statistically significant at the significance level of $(\alpha \leq 0.05)$, freedom degrees (223), and the tabular value of ( $\mathrm{t})$ (1.96).

It is clear from the results of Table (120 that there are no statistically significant differences at the significance level of (a-0.05) in the first and second domains and the domain of the degree of the availability of the self and human skills among the military training officers in dealing with the students of Al-Istiqlal University from the viewpoint of the students themselves which are due to the variable of gender (male, female).

Researchers ascribe this result to the fact that all the students of Al-Istiqlal University recognize in an approximate and equal way the self and human skills which their officer's trainers have.

This reflects their (the trainers) adoption of methods of training and unified dealing with all the students of the University including the males and the females in addition to the unity of instructions and trainings which they receive. 
This is reflected in their responses to the instrument of the study without considering the gender of the student. Also the scientific rehabilitation to which all the students are subjected is the same which means their implicit agreement on the most important self and human skills which the officers or the leaders should be endowed with.

The Second Hypothesis of the Study the Text of Which is: There are no statistically significant differences at the significance level of (a-0.05) in the degree of the availability of the self and human skills among the military training officers in dealing with the students of Al-Istiqlal University from the viewpoint of the students themselves which are due to the variable of the faculty (Humanities, Law and Police Sciences, Administrative Sciences, Medium Community College).

In order to test this hypothesis, the researchers used the One Way ANOVA. The results of Table (13) indicate this.

Table (13): Results of the One Way ANOVA for Testing the Significance of the Differences According to the Variable of the Faculty

Domain Sources of Variance Sum of Squares Degrees of Freedom

Axis of $\quad 3.594 \quad 3$

Human Skills through Groups $\quad 135.506 \quad 221$

Total $\quad 139.100$

Axis of $\quad$ Among Groups $\quad 5.431 \quad 224$

$\begin{array}{lll}\text { Self-Skills } \quad \text { Through Groups } & 142.858\end{array}$

Total 148.289

Total degree Among Groups $\quad 4.098 \quad 3$

Through Groups $\quad 128.286 \quad 221$

$\begin{array}{lll}\text { Total Degree } & 130.384 & 224\end{array}$

Table (13) Continued

Value of F Significance Level 

1.954
0.122
2.801
$0.041^{*}$
2.390
0.070

* Statistically significant at the significance level of $(\alpha \leq 0.05)$

It is clear from the results of Table (13) that there are no statistically significant differences at the significance level of $(\alpha \leq 0.05)$ in the degree of the availability of the self and human skills among the military training officers in dealing with the students of Al-Istiqlal University from the viewpoint of the students themselves which are due to the variable of the faculty in the first domain which is related to the axis of the human skills and the total degree, whereas there were statistically significant differences at the significance level of $(\alpha \leq 0.05)$ in the axis of the selfskills. To know in favour of which are these differences, the two researchers used the (LSD) test. Table (14) clarifies the results of this test.

Table (14): Results of Using the LSD Test (less statistical Significance) For Dimensional Comparison between the Mediums of the Faculty Categories in the Self-Skills Axis
Axis Faculty Humanities Law
Administrative Community

\section{Police Sciences Sciences College}

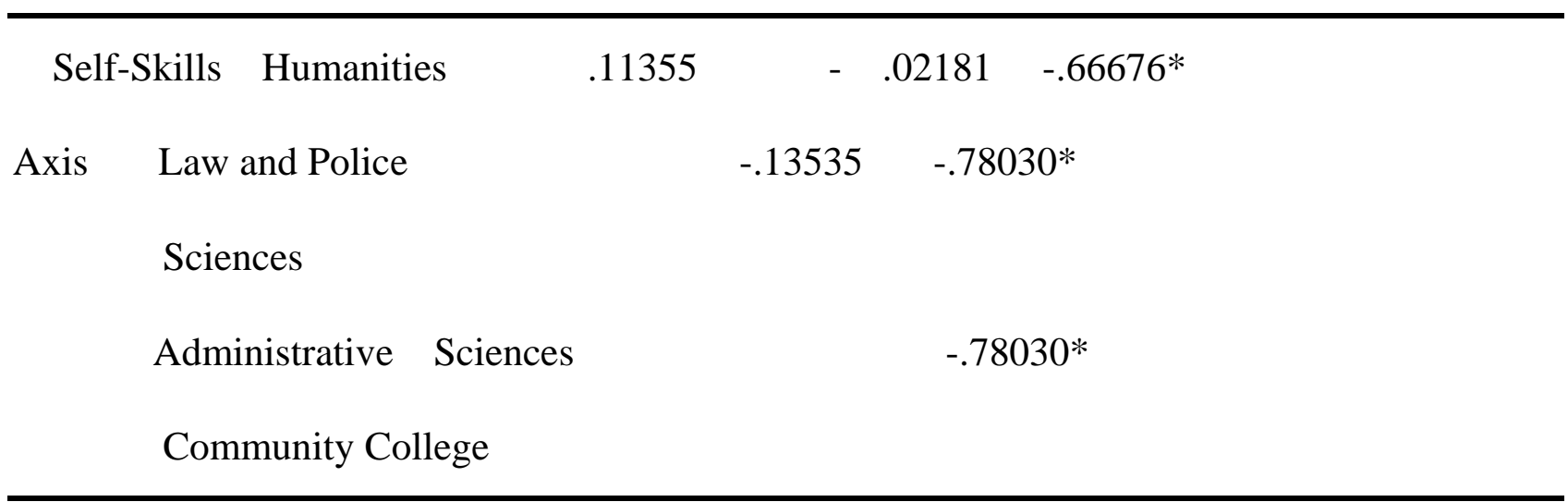

It is indicated from Table (14) that there are statistically significant differences in the degree of the availability of the self and human skills among the military training officers in dealing with the students of Al-Istiqlal University from the viewpoint of the students themselves which are due to the variable of the faculty and in favour of the Medium Community College over the Faculty of Humanities and the Faculty of Administrative Sciences. 
The two researchers ascribe this result to the fact that all the University students from the Bachelor's level receive similar training throughout the four years (the study period to obtain the Bachelor's degree). This was reflected in their arithmetic means in the tables which were previously mentioned, in contrast with the Diploma students who are subjected to an intensive training program which extends to two years (the study period to obtain the Diploma degree). Concentration is on their different personal traits and the skills of the mental abilities besides the skill of self-control and governing and controlling themselves. This reflected their responses on them in a clearer way than what they are among the Bachelor's students whereby the differences were in their favour.

The third hypothesis of the study the text of which is: There are no statistically significant differences at the significance level of (a-0.05) in the degree of the availability of the self and human skills among the military training officers in dealing with the students of Al-Istiqlal University from the viewpoint of the students themselves which are due to the variable of the level of the study year (First, Second, Third, Fourth).

In order to test this hypothesis, the researcher used the One-Way ANOVA test. The results of Table (15) indicate this

Table (15): Results of the One-Way ANOVA test for testing the differences according to the variable of the level of study year

\begin{tabular}{lccc}
\hline Domain & Source of Variance & Sum of Squares & Degrees of Freedom \\
\hline Human Skills & among Groups & 11.144 & 3 \\
Axis & through Groups & 127.956 & 221 \\
& Total & 139.100 & 224 \\
\hline Self-Skills & Among Groups & 10.417 & 3 \\
Axis & through Groups & 137.872 & 221 \\
& Total & 148.289 & 224 \\
\hline Total Degree & among Groups & 10.785 & 3 \\
& Through Groups & 119.599 & 221
\end{tabular}


Total

Table (15) Continued

Medium of Squares

3.715

.579

3.472

.624

3.595

130.384

224

F Value Significance Level

$6.416 * .001$

$5.566 * .001$

* Statistically significant at the significance level of $(\alpha \leq 0.05)$

It is clear from Table (15) that there are statistically significant differences at the significance level of $(\alpha \leq 0.05)$ in the degree of the availability of the self and human skills among the military training officers in dealing with the students of Al-Istiqlal University from the viewpoint of the students themselves which are due to the variable of the faculty in the first domain which is related to the axis of the human and life skills and the second domain which is related to the self-skills and the total degree. To know in favour of whom these differences are, the researchers used the (LSD) test. Table (16) clarifies the results of this test.

Table (16): Results of Using the (LSD) test (Less Statistical Difference) for Dimensional Comparison between the Mediums of the Categories of the Study Year Level in the Axes of the Study

\begin{tabular}{|c|c|c|c|c|c|c|}
\hline Axis & \multicolumn{2}{|c|}{ Level of Study Year } & \multirow[t]{2}{*}{ First } & \multirow{2}{*}{$\begin{array}{r}\text { Second } \\
.26601\end{array}$} & \multirow{2}{*}{$\begin{array}{l}\text { Third } \\
.69151 *\end{array}$} & \multirow{2}{*}{$\begin{array}{l}\text { Fourth } \\
.50100^{*}\end{array}$} \\
\hline \multirow{4}{*}{\multicolumn{2}{|c|}{ Axis of Skills }} & First & & & & \\
\hline & & Second & & & $.42550 *$ & .23499 \\
\hline & & Third & & & & -1.9051 \\
\hline & & Fourth & & & & \\
\hline
\end{tabular}

Axis of Self

Skills

First

.18522

$.64283 * .44568^{*}$

Second

$.45760 * \quad .26046$ 
Third

Fourth

\begin{tabular}{llccc} 
Total Degree & First & .22929 & $.66938^{*}$ & $.47585^{*}$ \\
& Second & & $.44009^{*}$ & .24657 \\
& Third & & -.19353 \\
& Fourth & & \\
\hline
\end{tabular}

It is indicated from the results of Table (16) that the differences were in all the axes of the study and the total axis was in favour of the First year over the Third year and the Fourth year and in favour of the Second year over the Third year.

Researchers ascribe this result to the fact that the students' being new in the University and specifically in their First year positively affects their degree of commitment and abidance with the University regulations and instructions and the degree of their compliance with the orders and prohibitions which are issued by the different specialized sources at the University as compared with the students of the following years. It is worth mentioning that the difference which is intended here is a difference in the degree of commitment and not in its absence.

The researchers also attribute this to the shock of the first experience of the military life of the students away from their civilian life and its flexibility and their application of the military instructions and laws in a strict way at the onset of their university life. This was reflected in their responses concerning the existence of the human and self-skills among the trainers according to their study year from the First year till the Fourth year.

\section{Recommendations}

In the light of the results brought about by the study, the researchers recommended the following:

- Reinforcing the human skills of the trainers specially the two skills of listening and problem solving.

- Reinforcing the self-skills of the trainers specially the personal traits, the mental abilities and self-control. 
O Providing the students with more security and academic trainings which develop in them these skills so that they become future leaders who are successful in the domains of work which are entrusted to them after their graduation.

○ Conducting future studies in the same domain so that they deal with other important variables on the training process, such as: the different training methods, the social skills, personality patterns among the trainers, methods of treatment......etc. and this is in order to tighten the ring on the best possible training systems.

\section{References}

\subsection{Arabic References}

○ 'Uthman, Farouq. (1997). The Strategies of Building the Behavioural Skills for the Administrative Leaders. Cairo: Dar Al-Ma'aarif.

○ Abu-Hashe, Asa'ad. (2007). The Effectiveness of Training On Self-Control in Lowering the Aggressive Behaviour Among a Sample of Juveniles at The Social Observation House. (Unpublished M.A. thesis). Jordan, Mu'ta University.

○ Al-Jayyousi, Muhammad and Jadallah, Jameela (2000). Administration: Science and Application. Amman: Dar Al-Maseera for Publishing and Distribution.

○ Al-Qurni, Muhammad Bin Muhsin (2007). The Attitudes of the Officers towards the Leadership Traits and Skills: An Applied Study on the Officers of the General Directorate of the Civil Defence in the Kingdom of Saudi Arabic. Unpublished M.A. thesis. Nayef's University for Security Sciences, Al-Riyadh, Saudi Arabia.

○ Al-Qurni, Muhammad. (1426 Hijra). The Attitudes of the Officers towards the Keadership Traits and Skills: An Applied Study on the Officers of the General Directorate of the Civil Defence in the Kingdom of Saudi Arabia. (Unpublished M.A.thesis). Al-Riyadh, Nayef's Arab University for Security Sciences.

○ Al-Tajem, Abdul-Ghani and Al-Sawwat, Talq. (199\%). The Organizational Behaviour: The Concepts, The Theories, The Applications, 3rd ed. Damascus: The Directorate of University Textbooks.

- Al-Tanani, Rami 'Umar (2010). The Skills of the Policeman in Dealing With the Public and Their Effect on the Efficiency of Providing Security Service:An Applied Study on the 
Policemen Working in the Gaza Governorate. Unpublished M.A. thesis. The Islamic University, Gaza, Palestine.

- Al-Thuwaibi, Fahd Bin Muhammad (2005). The Administrative and Personal Skills and Their Relationship with the Public; A Survey Study on the Officers Working in the Police Force of Al-Qaseem Area. Unpublished M.A. thesis. Nayef's University for Security Sciences. Al-Riyadh, Saudi Arabia.

○ Al-Waheebi, Khaled. (2005). The Role of Leadership Rehabilitation Programs in Developing the Security Leadership Skills. (Unpublished M.A. thesis). Al-Riyadh, Nayef's Arab University for Security Sciences.

- Darweesh, Abdul-Kareem and Takla, Layla. (1995). Fundamentals of Public Administration. Cairo: The Anglo-Egyptian Press.

○ Darweesh, Ibraheem. (1988). Al-Waseet (Intermediary) in Public Administration. Cairo: Egyptian General Commission of Writers.

○ Dosh, Bander Ali (2006). The Role of Security Skills in Raising the Performance Level: A Survey Study of the Directors of the Holy Capital Police Stations. Al-Riyadh. Unpublished M.A. thesis. Nayef's University for Security Sciences. Al-Riyadh, Saudi Arabia.

○ Hameed, Muhammad and Al-Ma'aaz, Muhammad. (1986). Public Administration Between Theory and Application. Cairo: Faculty of Commerce.

○ Kan'aan, Nawaa' (1985). The Administrative Leadership, 3rd ed.Al-Riyadh: Al-Farazdaq Presses.

○ Kurdieh, Ayman Zaki (2011). The Skills of the Health Cadre in Dealing with the Public and Their Effect on the Efficiency of the Health Service from the Viewpoint of the Public of the Revising Patients. Unpublished M.A. thesis. The Islamic University, Gaza, Palestine.

○ Shareef,'Ali (1987). Managing the Public Organizations. Alexandria: The University House for Publishing and Distribution.

○ Sheeha, Ibraheem. (1983). Public Administration. Beirut: The University House for Printing and Publication.

\subsection{English References}

○ Fletcher, J.D. \& Chatelier, P.R. (2000). An overview of Military Training. Institute for the Defence Analyses, Virginia, United States.

○ Gilliland. (1989). Theories and Strategies in Counselling Psychotherapy. Prentice Hall Englewood Cliffs, New Jersey. 
- Matin, Hassan Z. Jandaghi, Golamreza, Haj Karimi, Fatime, Hamidzadeh, ‘Ali (2010). Relationship between Interpersonal Communication Skills and Organizational Commitment: Case Study: Jahad Keshavarzi University of Qom, Iran. European Journal of Sciences, Volume 13, Number 3.

\subsection{Electronic References}

○ Military Training Commission-Palestine. 14/3/2020 http://www.gmtc.ps

○ The Sultan Qabous Academy for Police Sciences 14/3/2020. http://sqaps.edu.om/?p=3442

○ Al-Musallah Magazine. 14/3/2020. http://www.almusallh.ly/ar/thoughts/40-vol-3

Copyright ( 2021 Dr. Amer Saber Shehadeh, Dr. Mohammad Taleb Dabous, Dr. Nader Taleb Shwamreh, AJRSP. This is an open-access article distributed under the terms of the Creative Commons Attribution License (CC BY NC).

Doi: doi.org/10.52132/Ajrsp.e.2021.305 